\title{
Inhibitory effect of Phyllanthus urinaria L. extract on the replication of lamivudine- resistant hepatitis B virus in vitro
}

Jaesung Jung ${ }^{1,2}$, Nam Keun Kim³ ${ }^{3}$ Sun Park ${ }^{1,2}$, Ho-Joon Shin ${ }^{1,2}$, Seong Gyu Hwang ${ }^{3,4^{*}}$ and Kyongmin Kim ${ }^{1,2^{*}}$

\begin{abstract}
Background: Long-term treatment of chronic hepatitis B (CHB) with nucleos(t)ide analogs results in the emergence of drug-resistant hepatitis B virus (HBV) harboring mutations in the polymerase (P) gene. The Phyllanthus extract has anti-HBV activity; however, its antiviral activity against lamivudine (LMV)-resistant mutants has not been examined.

Methods: HBV harboring LMV-resistant mutations (rtM204I, rtM204V, and rtM204S) in the P gene at the YMDD $\left({ }^{203}\right.$ tyrosine-methionine-aspartate-aspartate $\left.{ }^{206}\right)$ reverse transcriptase (RT) active site were generated and their sensitivity to Phyllanthus urinaria koreanis extract examined. Southern blotting and real-time PCR were used to determine the concentration of plant extract required to inhibit HBV DNA synthesis by 50 and $90 \%$ (EC 50 and $\mathrm{EC}_{90}$, respectively). An enzyme-linked immunosorbent assay was used to measure the $\mathrm{EC}_{50}$ of $\mathrm{HBV}$ surface antigen ( $\mathrm{HBs} A \mathrm{Ag})$ and $\mathrm{HBV}$ core antigen ( $\mathrm{HBCAg}$ ) secretion, and the $50 \%$ cytotoxic concentration of the extract was measured in a 3-(4,5-dimethylthiazol-2-yl)-2,5-diphenyltetrazolium bromide assay. Real-time RT-PCR was used to measure mRNA expression levels.

Results: The expression of intracellular HBV DNAs in HBV WT- or mutant-transfected HepG2 cells decreased upon treatment with Phyllanthus extract. The secretion of HBsAg and HBcAg also fell in a dose-dependent manner. Phyllanthus extract induced interferon-beta (IFN- $\beta$ ), cyclooxygenase-2 (COX-2), and interleukin-6 (IL-6) mRNA expression in HBV WT-transfected HepG2 cells, possibly via activation of extracellular signal-regulated kinases and c-jun N-terminal kinases and the induction of retinoic acid inducible gene-l, toll-like receptor 3, myeloid differentiation primary response gene 88 , and/or tumor necrosis factor receptor-associated factor 6 gene expression. HBV transfection in the absence of extract or exposure of cells to extract alone did not trigger these signaling cascades.
\end{abstract}

Conclusions: Phyllanthus extract inhibited HBV DNA synthesis and HBsAg and HBCAg secretion by replicating cells harboring HBV wild-type and LMV-resistant mutants, likely by inducing the expression of IFN- $\beta$, COX-2, and IL-6. These data indicate that Phyllanthus extract may be useful as an alternative therapeutic agent for the treatment of drug-resistant CHB patients.

Keywords: Phyllanthus extract, Hepatitis B virus DNA synthesis, Lamivudine-resistant HBV

\footnotetext{
* Correspondence: sghwang@cha.ac.kr; kimkm@ajou.ac.kr

${ }^{3}$ Institute for Clinical Research, CHA Bundang Medical Center, CHA University,

Seongnam, Gyeonggi-do, Korea

'Department of Microbiology, Ajou University School of Medicine,

Woncheon-dong 5, Suwon 443-721, Korea

Full list of author information is available at the end of the article
} 


\section{Background}

More than 2 billion people worldwide are infected with the hepatitis B virus (HBV), of whom 400 million are chronically infected. A significant fraction of chronically infected individuals develop liver cirrhosis and hepatocellular carcinoma [1, 2], and approximately 1 million die annually from $\mathrm{HBV}$-induced liver disease [3]. $\mathrm{HBV}$ is a small, enveloped DNA virus belonging to the Hepadnaviridae family, which replicates preferentially in liver cells and utilizes a unique replication strategy involving the reverse transcription of pregenomic RNA (pgRNA) [4].

Interferons (IFNs) and several nucleos(t)ide analogs including lamivudine (LMV), adefovir dipivoxil (ADV), entecavir (ETV), tenofovir (TDF), and telbivudine (LdT), are approved for the treatment of chronic hepatitis $\mathrm{B}(\mathrm{CHB})$ in most countries [5]. The low response rate and side effects associated with IFNs mean that nucleos(t)ide analogs are used most often. Nucleos(t)ide analogs inhibit the reverse transcriptase (RT) activity of the HBV DNA polymerase (P), thereby interrupting the elongation of newly synthesized DNA. The drugs also lower alanine aminotransferase levels, reduce serum HBV DNA levels, and induce seroconversion of HBV e antigen ( $\mathrm{HBeAg}$ ) to anti-HBe in $\mathrm{CHB}$ patients.

LMV was the first nucleoside analog to be licensed (in 1998); however, $80 \%$ of patients become resistant after 5 years of therapy [5-8]. The most common mutation associated with LMV resistance is the substitution of methionine 204 with isoleucine, valine, or serine (M204I/V/S) at the YMDD active site motif within the P protein RT domain [9-11]. The L80V/I mutation was first detected in patients with severe hepatitis after apparent LMV failure [12]. Mutation at the L180 or A181 residues also contributes to LMV resistance [13]. M204V/I mutations associated with LMV and LdT resistance also confer cross-resistance to other L-nucleosides and reduce sensitivity to ETV (but not to ADV or TDF) [10, 13-17]. ADV-resistance also becomes a limiting factor for treatment, although it develops more slowly than resistance to LMV [18]. Like ADV, TDF (a methyl derivative of ADV) exhibits antiviral activity against LMV-resistant HBV [19], although it is more potent than ADV and the rate of emergence of resistant mutants is slower. However, high doses of TDF and ADV cause nephrotoxicity in CHB patients [8]. Also, because nucleos(t)ide analogs do not prevent the initial formation of covalently closed circular DNA, new cells can be infected during therapy due to the persistent viremia [20].

Several molecules, such as phenylpropenamide derivatives (AT-61 and AT-130) and heteroaryl-pyrimidines (HAP), have been developed to circumvent drugresistant $\mathrm{CHB}$. Phenylpropenamide derivatives inhibit encapsidation of HBV wild-type (WT) and LMVresistant mutant pgRNA in vitro [21, 22]; however, clinical trials were discontinued due to toxicity [23]. A Phase I clinical trial of HAP, which inhibits HBV core (C) protein dimerization and blocks nucleocapsid formation, has been conducted [24, 25] and both RNAi [26, 27] and inhibitors of a newly identified HBV receptor, sodium taurocholate polypeptide, are being tested [28].

In Asian countries, traditional medicinal herbal extracts have been used to treat chronic liver disease for thousands of years, and modern technology has confirmed their efficacy. Since herbal extracts have been used by millions of people over thousands of years, their safety and low toxicity are strong assets. Several studies describe the anti-HBV activity of traditional herbal extracts. For example, chlorogenic acid, quinic acid, and caffeic acid from the leaves and fruits of the coffee plant [29], Curcuma longa Linn extract [30], Jasminum officinale L. var. grandiflorum [31], emodin (1,3,8-tri-hydroxy-6-methylanthraquinone) [32], oxymatrine from Sophora radix [33], and wogonin from Scutellaria baicalensis Georgi [34] all suppress HBV replication in vitro and/or in vivo.

Phyllanthus species (Phyllanthaceae family) have been used to treat a number of diseases, including human bone disorders [35] and diabetes [36], and show antiviral activity against human immunodeficiency virus [37] and HBV [38-41]. Phyllanthus inhibits the activity of hepadnaviral P protein, the secretion HBsAg [38], and transcription of mRNA for the surface (S) protein by specifically interacting with $\mathrm{HBV}$ enhancer I [39] and the pre-S1 promoter [40]. It also inhibits viral entry, viral assembly, or virion release by inducing the expression of annexin A7 [41].

The results indicated that Phyllanthus urinaria koreanis extract inhibits HBV DNA synthesis and HBsAg and $\mathrm{HBcAg}$ secretion by LMV-resistant HBV mutants in vitro. It was also evident from the result this did not occur via the inhibition of core particle formation and pgRNA encapsidation. Increased expression of IFN- $\alpha$, cyclooxygenase-2 (COX-2), and interleukin-6 (IL-6) mRNA by extract-treated HepG2 cells containing replicating HBV may be due to the induction of retinoic acid inducible gene-I (RIG-I), toll-like receptor 3 (TLR-3), myeloid differentiation primary response gene 88 (MyD88), and/or tumor necrosis factor receptor-associated factor 6 (TRAF-6) expression. Taken together, we suggest that Phyllanthus extract inhibits HBV replication in HBV WT and LMV-resistant-infected HepG2 cells via the COX-2 and IL-6 signaling pathways.

\section{Methods}

\section{Preparation of Phyllanthus urinaria koreanis aqueous} extract

Phyllanthus urinaria koreanis was provided by Hepaguard Research Laboratories Co. A dried leaf of Phyllanthus 
was ground up and then extracted with water according to the method described by Shin et al. [42]. The aqueous extract was then dried to a powder, dissolved in phosphate buffered saline (final concentration, $100 \mathrm{mg} /$ $\mathrm{mL}$ ), and stored at $-20{ }^{\circ} \mathrm{C}$ until required. Skin Biotechnology Center of Kyung Hee University determined chemical composition of the extract by liquid chromatography/quadruple time-of-flight mass spectrometry (LC-qTOF-MS) (Fig. 1).

\section{Construction of HBV P protein YMDD motif mutants}

The full-length monomeric HBV genome was PCRamplified and subcloned into the Sac I/Sap I sites in pBluescript SK (Promega) to generate pBluescript-HBV WT. The YMDD ( ${ }^{203}$ tyrosine-methionine-aspartate-aspartate $^{206}$ ) RT active site mutants M204A, M204I, M204K, M204L, M204R, M204T, and M204V, were then constructed by PCR-derived mutagenesis. To generate replication competent HBV WT and mutants, the EcoR I-Sac II fragment from pBluescript-HBV WT and the various YMDD mutants were inserted into $\mathrm{pPB}$, a partially redundant WT HBV subtype adw R9 plasmid [43]. To generate the YSDD variants, Met 204 (ATG) was changed to Ser (TCG) using a fusion PCR technique. PCR-derived DNA fragments were generated using the mutagenic primer pairs, $5^{\prime}$-TTT CAG TTA TTC GGA TGA TGT GGT ATT G- $3^{\prime}$ and 3'- CA AAC CGA AAG TCA ATA AGC CTA CTA CAC- 5' (mutated sequences in bold and underlined), digested with Xcm ISac II, and inserted into the HBV WT construct to yield the YSDD mutant. All constructs containing PCR-derived DNA fragments were then sequenced to confirm the presence of specific mutations and the absence of extraneous mutations introduced during the PCR reaction.

\section{Cell culture, transfection, and isolation of core particles}

HepG2 cells (a hepatocellular carcinoma cell line) were maintained in Dulbecco's modified Eagle's medium (DMEM) (Gibco Life Technologies, Grand Island, NY, USA) supplemented with $10 \%$ heat inactivated fetal bovine serum and $1 \%$ penicillin/streptomycin under a humidified atmosphere at $37{ }^{\circ} \mathrm{C}$ containing $5 \% \mathrm{CO}_{2}$. Cells were transfected with $8 \mu \mathrm{g}$ of HBV WT or mutant construct using lipofectamine 2000 (Invitrogen, Carlsbad, CA, USA), according to the manufacturer's instructions. Cytoplasmic core particles were prepared 3 days posttransfection, as previously described [43]. Transfection experiments were repeated a minimum of three times.

\section{Southern blotting}

To analyze HBV DNA synthesis by Southern blotting, HBV DNA extracted from isolated core particles was separated by agarose gel electrophoresis and hybridized to a ${ }^{32} \mathrm{P}$-labeled random-primed probe specific for the full-length HBV sequence, as described previously [43]. The relative intensities of HBV double-stranded linear

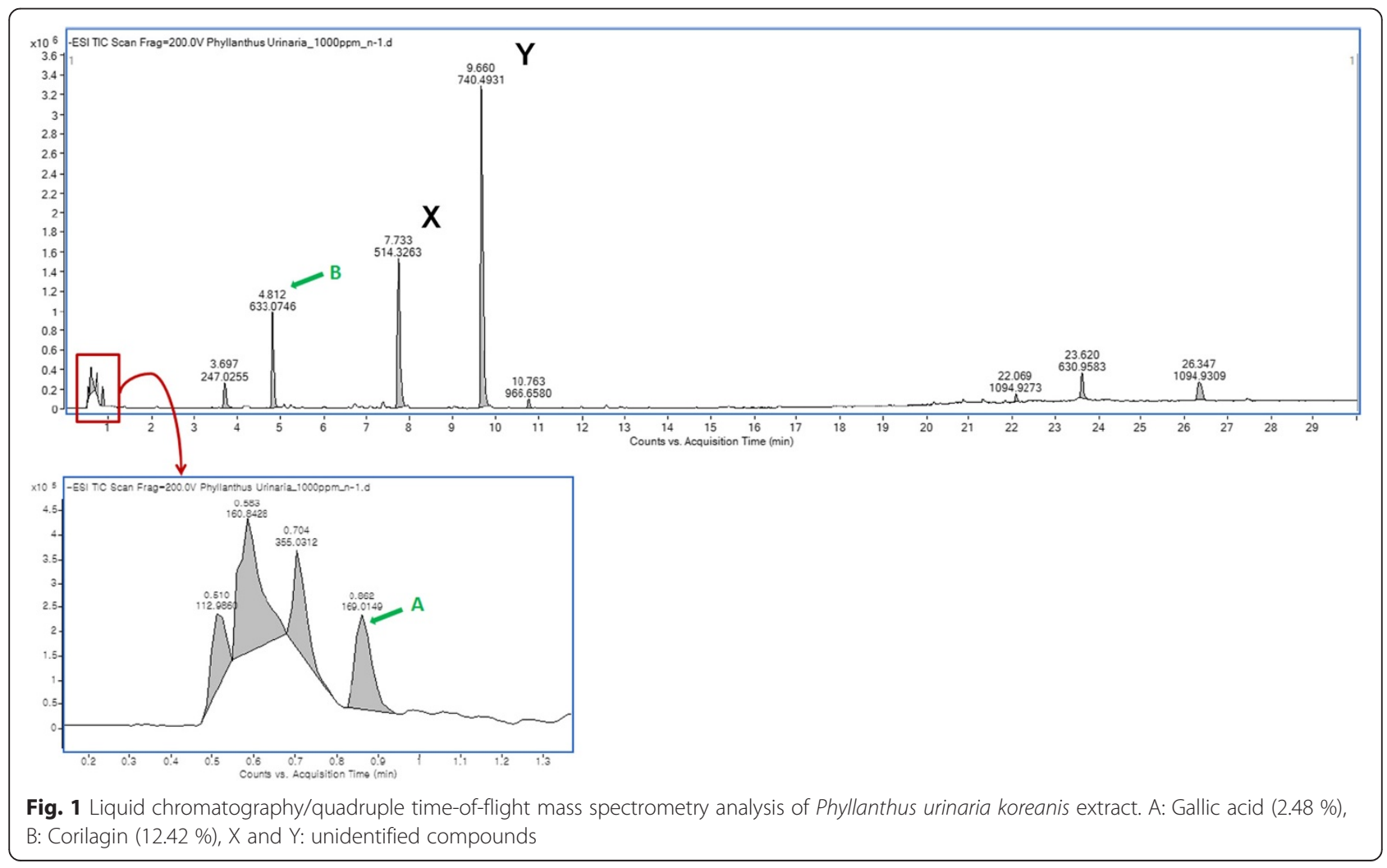


(DL) DNA were measured using the Fujifilm Image Gauge V4.0 program (Fuji Film Science lab 2001).

\section{Western blotting}

Isolated core particles were electrophoresed on a $1 \%$ native agarose gel and transferred to polyvinylidene fluoride (PVDF) membrane and then immunoblotted with a polyclonal rabbit anti-HBc antibody (1:1,000; Dako, Glostrup, Denmark), as described previously [43]. Bound antibody was detected with a horseradishperoxidase (HRP)-conjugated anti-rabbit secondary antibody (Dako) followed by enhanced chemiluminescence (ECL; Amersham, Piscataway, NJ, USA). Total cell lysates were then subjected to SDS-PAGE and the resolved proteins transferred to a PVDF membrane. The membrane was then incubated with monoclonal mouse anti-tubulin (1:1,000; Calbiochem, San Diego, CA, USA), polyclonal rabbit anti-COX-2 (1:1,000; Santa Cruz Biotechnology, Santa Cruz, CA, USA), polyclonal rabbit anti-extracellular signal-regulated kinase (ERK) and anti-p-ERK (1:1,000; Cell Signaling Technology, Danvers, MA, USA), polyclonal rabbit anti-c-jun Nterminal kinase (JNK) and anti-p-JNK (1:1,000 Cell Signaling Technology), polyclonal rabbit anti-p38 and anti-p-p38 (1:1,000 Cell Signaling Technology), or polyclonal rabbit anti-luciferase (1:500; Santa Cruz Biotechnology) antibodies. Immunoreactive bands were visualized using a HRP-conjugated secondary antibody (Dako) followed by ECL. Relative band intensities were measured using the Fujifilm Image Gauge V4.0 program.

\section{RNase protection analysis (RPA)}

An RPA was performed as described previously [43] to analyze the encapsidated and cytoplasmic pgRNA. Radiolabeled anti-sense probes (446 nucleotides (nts); nts 1805-2187 of HBV sequence) were synthesized in vitro; the protected sequence comprised 369 nts. The relative levels of cytoplasmic pgRNA and pgRNA obtained from isolated core particles were measured using the Fujifilm Image Gauge V4.0 program.

\section{Cell cytotoxicity assay}

An MTT (3-[4,5-dimethylththiazol-2-yl]-2,5-diphenyltetrazolium bromide) assay was performed to examine the cytotoxic effects of the extracts on HepG2 and Huh7 cells. Cells were grown in 96-well microplates and then incubated with serial dilutions of each extract for $48 \mathrm{~h}$ at $37{ }^{\circ} \mathrm{C}$. Cell viability was examined after replacing the culture medium with $100 \mu \mathrm{L}$ MTT in DMEM. After $3 \mathrm{~h}$, $100 \mu \mathrm{L}$ dimethyl sulfoxide was added to dissolve formazan of MTT. The absorbance at $570 \mathrm{~nm}$ was measured in a plate reader. The $\mathrm{CC}_{50}$ (defined as the concentration of extract that reduced cell viability to $50 \%$ of that of the control) was then calculated.
Quantitative real-time PCR (qPCR) and real-time RT-PCR HBV DNA extracted from isolated intracellular core particles was analyzed by real-time quantitative PCR in an ABI 7000. The PCR primers (forward primer: HBV, 5'GAC CAC CAA ATG CCC CTA TC-3'; reverse primer: HBV, 5' - GAG ATT GAG ATC TTC TGC GAC-3') encompass nts 2301-2443 and overlap the C protein Cterminus and $\mathrm{P}$ protein $\mathrm{N}$-terminus. The cycling program was as follows: denaturation at $95^{\circ} \mathrm{C}$ for $30 \mathrm{~s}$, followed by 40 cycles of $95^{\circ} \mathrm{C}$ for $5 \mathrm{~s}$ and $60^{\circ} \mathrm{C}$ for $31 \mathrm{~s}$. Each reaction was performed in a well of a 96-well PCR plate in a volume of $20 \mu \mathrm{L}$. HBV DNA was quantified using a standard curve. Standard curve was constructed from a serial dilution of HBV WT plasmid with known molecular weight and copy numbers. Total RNA was extracted from cells using RNA isoplus (Takara, Otsu, Shiga, Japan), according to the manufacturer's instructions. Real-time RT-PCR was then performed to measure the amount of COX-2, IL-6, TNF- $\alpha$, IFN- $\beta$, OAS, PKR, RIG-I, TLR-3, MyD88, and TRAF- 6 gene mRNA. Briefly, $5 \mu \mathrm{g}$ of RNA was reverse transcribed using oligo-dT and the cDNA subjected to quantitative real-time PCR. The primers used for realtime PCR and real-time RT-PCR are listed in Additional file 1.

\section{Results}

\section{Composition of the Phyllanthus urinaria koreanis extract}

The amounts of the four major components of Phyllanthus extract (corilagin, gallic acid, quercetin, and geraniin) were determined by LC-qTOF-MS, as previously described $[44,45]$. In agreement with a previous report [44], corilagin (12.42\%) was detected as a major peak. Gallic acid (2.48 \%) was also detected, but the peak was small (Fig. 1). However we could not detect quercetin (MW, 302) or geraniin (MW, 952), and we were unable to identify the other major peaks shown in Fig. 1. From these, we could exclude the possibility that quercetin and geraniin may be responsible for the anti-HBV activity of Phyllanthus extract. Since we could not identify the other major peaks as specific compounds, they may therefore play a role in anti-HBV activity.

\section{Phyllanthus extract inhibits HBV DNA synthesis without affecting core particle formation and pgRNA encapsidation}

We next examined HBV C protein expression, core particle formation, pgRNA expression and encapsidation, HBsAg and HBcAg secretion, and DNA synthesis in HBV WT-transfected/Phyllanthus extract-treated HepG2 cells (Fig. 2). In agreement with previous reports [38-41], treating cells with different concentrations of extract led to a dose-dependent reduction in intracellular HBV DNA synthesis and in the level of $\mathrm{HBsAg}$ and $\mathrm{HBcAg}$ secretion (Fig. 2a-b; lanes 3 and 4). Treatment with LMV $(4 \mu \mathrm{g} / \mathrm{mL})$ 
led to a significant reduction in HBV DNA synthesis (Fig. 2a, lane 2) without affecting the secretion of HBsAg and HBcAg (Fig. 2b, lane 2).

It is not known whether Phyllanthus extract affects $\mathrm{C}$ protein expression, core particle formation, and pgRNA encapsidation; therefore, we next examined these parameters in HBV WT-transfected/extract-treated HepG2 cells (Fig. 2c-d). Of note, because pgRNA transcription in WT and LMV-resistant mutants was under the control of the cytomegalovirus immediate early (CMV IE) promoter, not the authentic precore/core promoter, pgRNA expression should not be affected by exposure to the extract. Even though the secretion of HBcAg fell upon exposure to the extract, neither $C$ protein expression nor core particle formation was affected (Fig. 2b and d). Also, pgRNA encapsidation was not affected (Fig. 2d). These results suggest that Phyllanthus extract inhibits HBV DNA synthesis and the secretion of HBsAg and $\mathrm{HBcAg}$ without affecting core particle formation and pgRNA encapsidation.
Effects of Phyllanthus extract on cell viability and HBV replication

Next, we performed an MTT assay to determine the $50 \%$ cytotoxic concentration $\left(\mathrm{CC}_{50}\right)$ of Phyllanthus extract for HepG2 cells. The mean $\mathrm{CC}_{50}$ of the extract was $757.0 \pm 56.5 \mu \mathrm{g} / \mathrm{mL}$ (Additional file 2), which was much higher than that for Huh7 cells $(130.1 \pm 5.1 \mu \mathrm{g} /$ $\mathrm{mL}$; Additional file 2).

We next determined the $50 \%$ effective concentration $\left(\mathrm{EC}_{50}\right)$ of Phyllanthus extract with respect to HBV WT DNA synthesis in HepG2 cells at 24 h post-transfection for $48 \mathrm{~h}$ extract treatment afterward. Southern blotting was then performed to measure the HBV DNA level in HBV WT-transfected/extract-treated HepG2 cells. The levels of double-stranded linear (DL) HBV DNA were quantified using Image Gauge V4.0. The $\mathrm{EC}_{50}$ and $\mathrm{EC}_{90}$ were $78.6 \pm 1.3$ and $154.8 \pm 11.8 \mu \mathrm{g} / \mathrm{mL}$, respectively (Table 1 ). The selectivity index (SI; $\mathrm{CC}_{50} / \mathrm{EC}_{50}$ ) for $\mathrm{HBV}$ WT DNA was 9.63 (Table 1). The $\mathrm{EC}_{50}$ of the extract with respect to $\mathrm{HBsAg}$ and $\mathrm{HBcAg}$ secretion was $252.5 \pm$

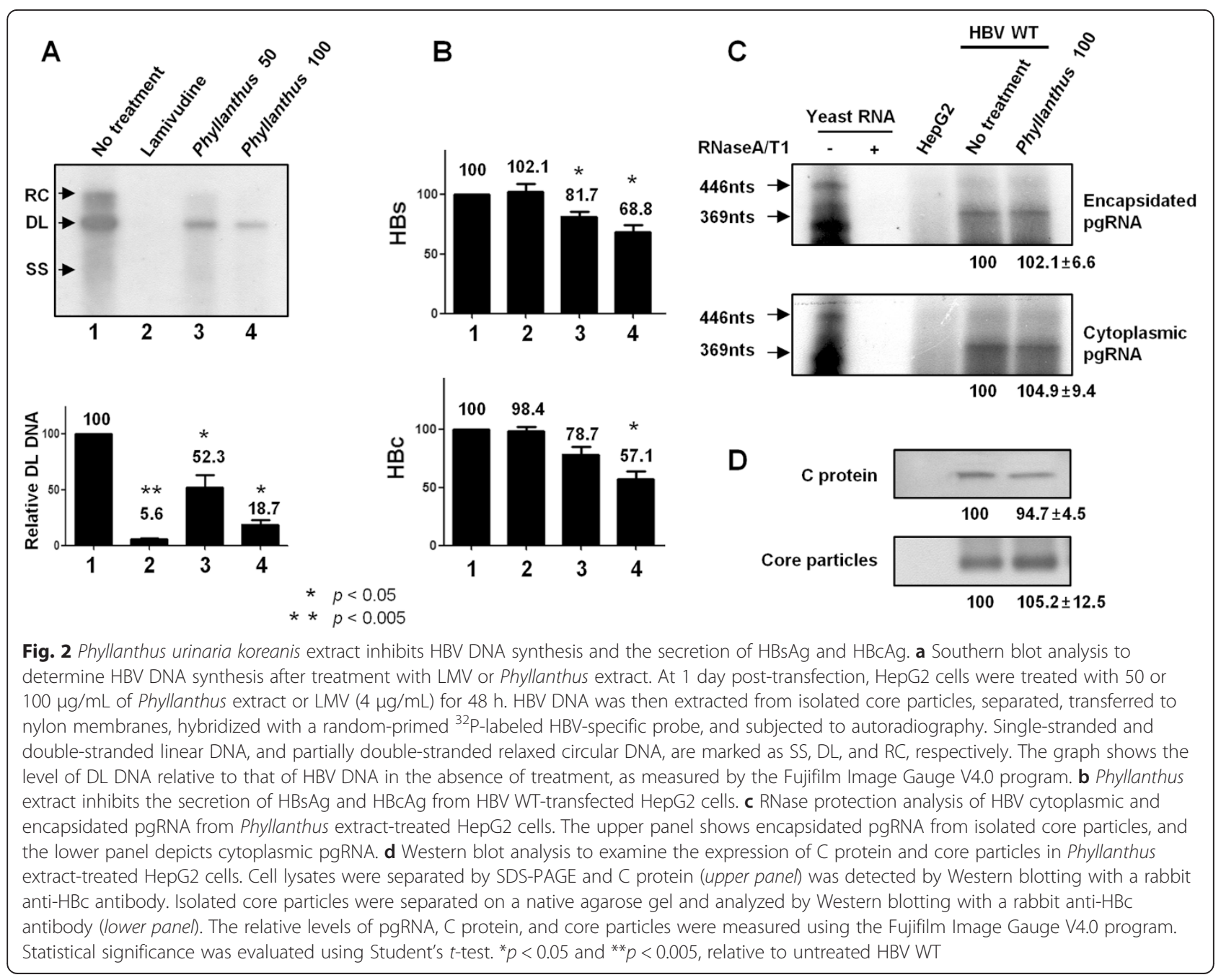


27.0 and $185.9 \pm 30.1 \mu \mathrm{g} / \mathrm{mL}$, respectively (as determined by enzyme-linked immunosorbent assay (ELISA)). The SIs for HBsAg and HBcAg secretion were 2.99 and 4.09, respectively (Table 1 ). The Southern blotting results were in agreement with those obtained by real-time PCR (Table 1).

\section{Replication of HBV P protein YMDD motif mutants} The conserved ${ }^{203} \mathrm{YMDD}^{206}$ motif within the RT catalytic $\mathrm{C}$ sub-domain of the HBV P protein is responsible for RNA- and DNA-dependent DNA polymerase activity. M204V or M204I are the most frequently observed mutations in this region, and confer resistance to LMV, LdT, and ETV $[16,17]$. A less frequently observed mutation following LMV treatment is M204S, although additional mutations can be found in different RT regions [11]. To investigate the inhibitory effect of Phyllanthus extract on LMV-resistant mutants, we substituted methionine 204 with alanine, isoleucine, lysine, leucine, arginine, serine, threonine, or valine to generate YADD, YIDD, YKDD, YLDD, YRDD, YSDD, YTDD, or YVDD, respectively (Fig. 3a). We then examined the replication of these mutants by Southern blot analysis (Fig. 3b, top panel). Single-stranded (SS), DL, and partially doublestranded relaxed circular (RC) HBV DNA molecules were detected in HBV WT- or mutant-transfected cells, albeit with different replication efficiencies (Fig. 3b, top panel). The transfection efficiency was normalized against luciferase expression (Fig. 3b, third panel). The amount of HBV DL DNA isolated from YIDD-, YLDD-, YSDD-, and YVDD-transfected cells was 105.8, 107.7, 94.2, and 92.4 \%, respectively, of that isolated from HBV WT (Fig. 3b, top and bottom panels). However, the amount of HBV DL DNA in YADD-transfected cells was $55.3 \%$ of that in HBV WT. HBV DNA synthesis was very inefficient in YKDD-, YRDD-, and YTDDtransfected cells, with HBV DL DNA levels being 21.3, 27.6, and $16.2 \%$ of that in the HBV WT-transfected cells
(Fig. 3b, top and bottom panels). Core particles were formed at comparable levels in mutant- and WTtransfected cells (Fig. 3b, 2nd panel).

Next, secretion of HBsAg and HBcAg was examined by ELISA. Overlap of the HBs open reading frame (ORF) with the $\mathrm{P}$ gene leads to an alteration in two amino acids (Ile195 and Trp196) in all mutants (except YLDD); this change is likely to affect HBsAg secretion. In agreement with a previous report [9], we observed reduced HBsAg secretion in cells transfected with YADD, YKDD, or YTDD (Fig. 3c). The level of HBsAg secretion from YSDD-transfected cells was low because the YSDD mutant harbored an ATT CGG sequence in the HBs ORF, which codes Ile195 and Arg196 (the same as the HBs-negative YKDD and YTDD mutants) (Fig. 3c). It should be noted here that the YSDD mutation identified in a LMV-resistant patient harbored AGT, coding for Ile195 and Val196 in the HBs ORF, and was HBsAg positive [11], whereas our constructed mutant harbored TCG. In contrast to a previous report [9], we found that the YRDD mutant secreted a very low level of HBsAg and replicated inefficiently (Fig. 3c). With the exception of the YTDD mutant, HBcAg secretion by the mutant viruses was comparable with that by HBV WT (Fig. 3c).

\section{Anti-HBV activity of Phyllanthus extract against the YMDD motif mutants}

HepG2 cells were transfected with HBV WT or YMDD motif mutants. Twenty-four hours later, the cells were exposed to Phyllanthus extract $(100 \mu \mathrm{g} / \mathrm{mL})$ for $48 \mathrm{~h}$. Replicative intermediate HBV DNAs isolated from intracellular core particles were then analyzed by Southern blot analysis (Fig. 4). Cells were treated with LMV (4 $\mu \mathrm{g} /$ $\mathrm{mL})$ and $\mathrm{ADV}(27.3 \mu \mathrm{g} / \mathrm{mL}$ or $100 \mu \mathrm{M})$ as controls (Fig. 4, lanes 2 and 3). HBV DL DNA synthesis in LMV-, ADV-, and Phyllanthus extract-treated HBV WTtransfected HepG2 cells was 6.5, 15.5, and $17.9 \%$ of that in untreated WT-transfected HepG2 cells (Fig. 4a).

Table 1 Phyllanthus urinaria koreanis extract inhibits replication of HBV WT and LMV-resistant mutants

\begin{tabular}{|c|c|c|c|c|c|c|c|c|c|c|}
\hline & \multicolumn{3}{|c|}{ HBV DNA by Southern blotting ${ }^{a}$} & \multicolumn{3}{|c|}{ HBV DNA by qPCR } & \multicolumn{2}{|l|}{$\mathrm{HBs} \mathrm{Ag}$} & \multicolumn{2}{|l|}{$\mathrm{HBC} A \mathrm{~g}$} \\
\hline & $\mathrm{EC}_{50}^{\mathrm{C}}$ & $\mathrm{EC}_{90}^{\mathrm{d}}$ & $\mathrm{Sl}^{\mathrm{e}}$ & $E C_{50}^{c}$ & $E C_{90}^{d}$ & $\mathrm{SI}^{\mathrm{e}}$ & $\mathrm{EC}_{50}^{c}$ & $\mathrm{SI}^{\mathrm{e}}$ & $E C_{50}^{c}$ & $\mathrm{Sl}^{\mathrm{e}}$ \\
\hline HBV WT & $78.6 \pm 1.3$ & $154.8 \pm 11.8$ & 9.63 & $119.8 \pm 21.2$ & $228.2 \pm 11.8$ & 6.31 & $252.5 \pm 27.0$ & 2.99 & $185.9 \pm 30.1$ & 4.09 \\
\hline YIDD & $82.3 \pm 18.6$ & $183.1 \pm 22.3$ & 9.19 & $125.2 \pm 18.6$ & $234.7 \pm 22.3$ & 6.04 & $239.5 \pm 16.3$ & 3.16 & $234.4 \pm 19.3$ & 3.23 \\
\hline YVDD & $104.6 \pm 9.2$ & $179.4 \pm 32.4$ & 7.23 & $126.1 \pm 9.2$ & $228.2 \pm 11.8$ & 6.00 & $263.7 \pm 10.4$ & 2.87 & $241.3 \pm 25.3$ & 3.14 \\
\hline YSDD & $90.1 \pm 13.2$ & $192.3 \pm 22.6$ & 6.91 & $139.8 \pm 33.7$ & $242.6 \pm 32.4$ & 5.4 & ND & ND & $195.6 \pm 20.2$ & 3.87 \\
\hline
\end{tabular}

Each value represents the mean \pm SD from three independent experiments. HBV DNA was extracted from isolated intracellular core particles after various concentrations of Phyllanthus urinaria koreanis extract treatment for $48 \mathrm{~h}$ from HBV WT and mutant-transfected HepG2 cells $N D$ not determined

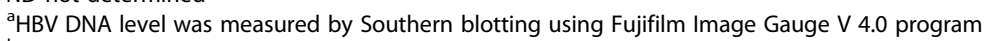

${ }^{b}$ HBV DNA level was measured by real-time quantitative PCR. Primers for pRCR are listed in Additional file 1

${ }^{\mathrm{C}} \mathrm{EC}_{50}$ is the concentration at which $50 \%$ depression of HBV DNA and HBs/e Ag secretion was observed

${ }^{\mathrm{d}} \mathrm{EC}_{90}$ is the concentration at which $90 \%$ depression of HBV DNA was observed

${ }^{e}$ Selectivity index $(\mathrm{SI})$ was calculated by $\mathrm{EC}_{50} / \mathrm{CC}_{50}$. $\mathrm{CC}_{50}$ of extract on HepG2 cells was $757.0 \pm 56.5 \mu \mathrm{g} / \mathrm{ml} . \mathrm{CC}_{50}$, the drug concentration that reduced cell viability to $50 \%$ of that the control was determined by MTT assay 


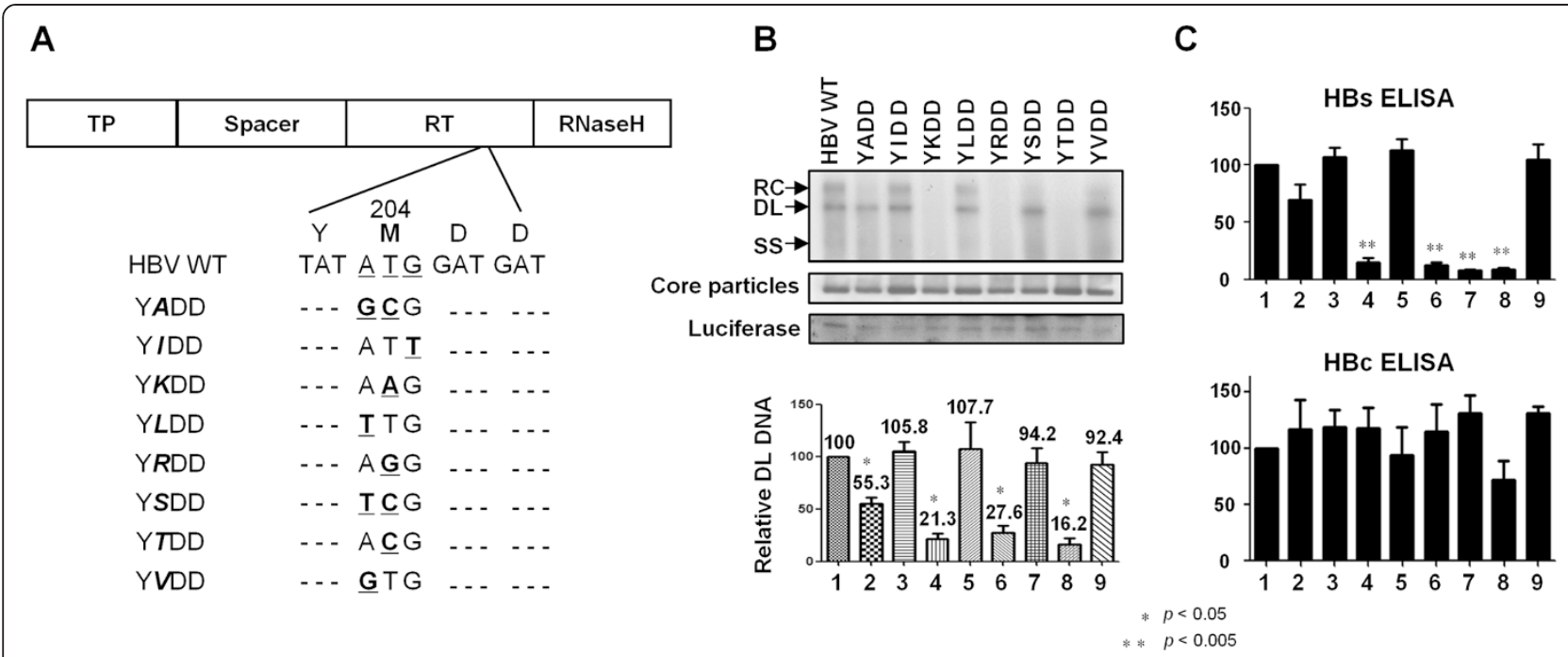

Fig. 3 Mutations within the YMDD motif of the HBV P protein, and HBV DNA synthesis, core particle formation, and HBsAg and HBCAg secretion in HBV WT- or YMDD motif mutant-transfected HepG2 cells. a Mutated sequences within the YMDD motif mutants. The mutated sequences are indicated by bold underlined letters. The substituted amino acid is indicated in bold italics. Y, tyrosine, $M$, methionine, D, aspartate, A, alanine; I, isoleucine; K, lysine; L, leucine; R, arginine; S, serine: T, threonine; V, valine. b HBV DNA synthesis and core particle formation in HBV WT- and YMDD motif mutant-transfected HepG2 cells. Southern blot and Western blot analyses of HBV DNA synthesis and core particle formation, respectively, in HBV WT- or YMDD motif mutant-transfected HepG2 cells was performed as described in Fig. 2a and d. Each transfection experiment was performed more than three times. Single-stranded and double-stranded linear, and partially double-stranded relaxed circular, DNA are marked as SS, DL, and RC, respectively. Relative levels of HBV DL DNA were quantified using Image Gauge V4.0. (Fuji film), and transfection efficiency normalized according to the level of luciferase expression. c ELISA to measure HBsAg or HBCAg secreted from HBV WT- and YMDD motif mutant-transfected HepG2 cells. At 3 days post-transfection, the culture supernatant was collected and the levels of secreted HBsAg and HBcAg were measured in an ELISA. Data are expressed as the mean \pm SD of three independent experiments. Statistical significance was evaluated using Student's $t$-test. ${ }^{*} p<0.05$ and ${ }^{* *} p<0.005$, relative to HBV WT

Similarly, LMV, ADV, and Phyllanthus extract inhibited HBV DNA synthesis in YADD-, YKDD-, YRDD- and YTDD-transfected HepG2 cells (Fig. 4b, d, f, and h). Consistent with previous reports, HBV DNA synthesis by YIDD and YVDD mutants was not inhibited by LMV treatment, confirming that these mutants were LMVresistant (Fig. 4c and i, lanes 3). However, HBV DNA synthesis by the YIDD and YVDD mutants was inhibited by ADV and Phyllanthus extract (Fig. 4c and i, lanes 2 and 4). This, Phyllanthus extract maybe a useful treatment for LMV-resistant CHB patients. A previous study demonstrated that the YSDD variant was LMV-resistant [11]; however, we found that HBV DNA synthesis by the YSDD mutant was only marginally inhibited by LMV (34.5 \% HBV DL DNA) (Fig. 4g, lane 3), indicating that an additional L180M mutation in the P gene [11] might confer LMV resistance. Nevertheless, ADV and Phyllanthus extract inhibited HBV DNA synthesis by the YSDD mutant more efficiently than LMV (Fig. 4g).

The $\mathrm{EC}_{50}$ and $\mathrm{EC}_{90}$ values for the Phyllanthus extract against HBV WT and the YIDD, YSDD, and YVDD mutants calculated after Southern blotting (Table 1) and real-time PCR were similar (Table 1, Fig. 4j). The $\mathrm{EC}_{50}$ for $\mathrm{HBsAg}$ and $\mathrm{HBcAg}$ secretion by the mutants were also determined by ELISA (Table 1), and showed that the SIs for the mutants were comparable with those for the WT. We could not determine the level of HBsAg in YSDD-transfected cells because they secreted low levels of HBsAg. Taken together, these results demonstrate that Phyllanthus extract inhibits both HBV DNA synthesis and HBsAg and HBcAg secretion by LMV-resistant mutants.

\section{Phyllanthus extract triggers intracellular signaling and} innate immune responses in HBV replicating HepG2 cells Medicines derived from plants inhibit viral production by inducing inflammatory responses and/or the production of pro-inflammatory cytokines [46, 47]. Here, we observed increased expression of mRNA for COX-2 and the pro-inflammatory cytokine, IL-6 (Fig. 5a). By contrast, there was no increase in the expression of mRNA for TNF- $\alpha$, another pro-inflammatory cytokine (Fig. $5 \mathrm{a}$ ). Although expression of IFN- $\beta$ mRNA increased in HBV WT-transfected/extract-treated cells, there was no change in the expression of mRNA for IFN-inducible genes such as OAS and PKR (Fig. 5b), suggesting that IFN may not exert antiviral activity via transcriptional upregulation of IFN-inducible genes in this HepG2transfected cell system. The significant reduction in HBV replication and the increased expression of IL-6 and 


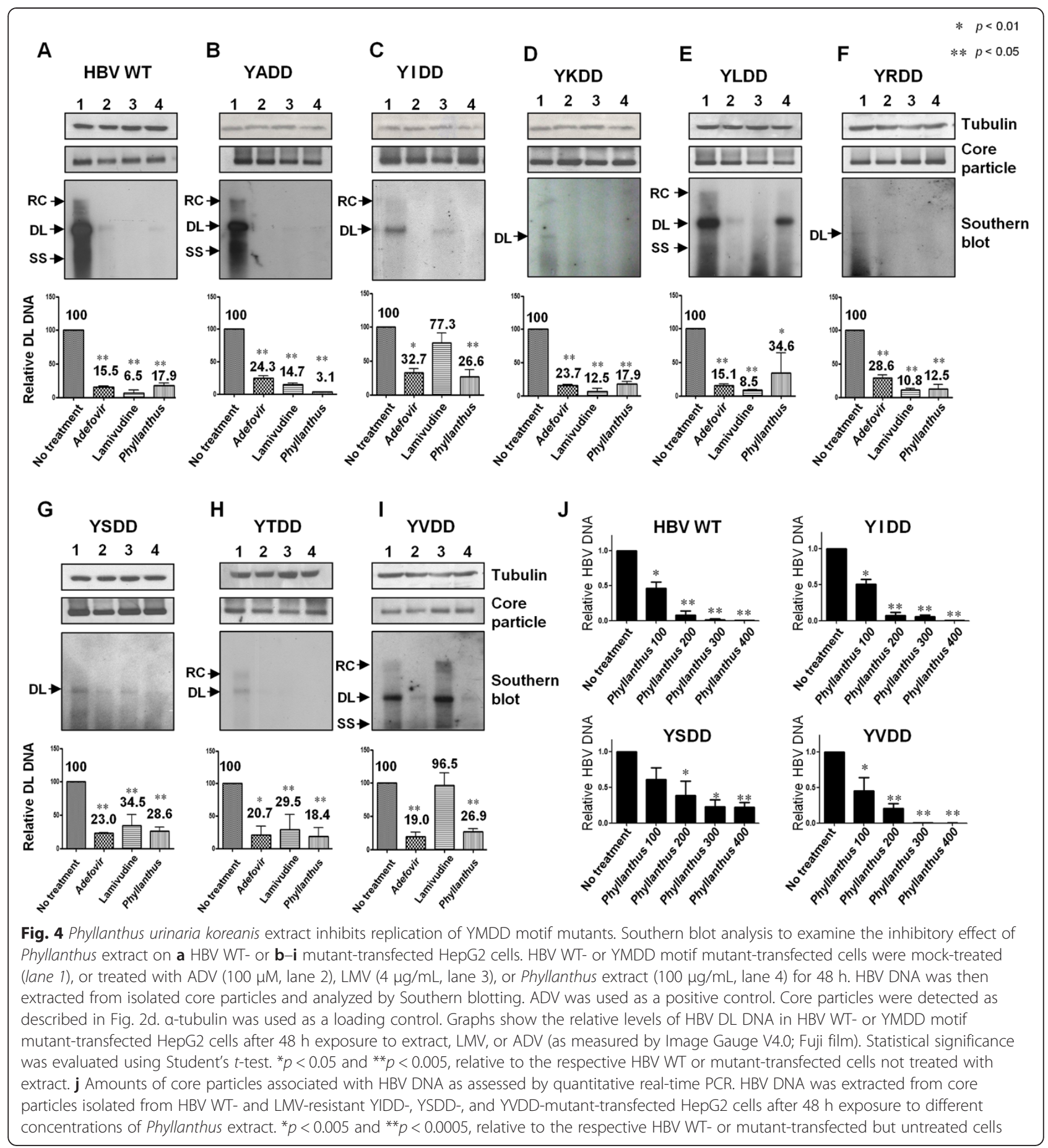

COX-2 in HBV WT-transfected/Phyllanthus extracttreated cells led us to hypothesize that upregulation of COX-2 and IL-6 mRNA occurs through transcriptional activation of innate immune signaling genes. We found that the expression of RIG-I, TLR-3, MyD88, and TRAF-6 mRNA increased in HBV WT-transfected/Phyllanthus extract-treated cells, but not in HBV WT-transfected cells or in cells treated with the extract alone (Fig 5c). This is suggestive of transcriptional activations of innate immune signaling genes. Also, phosphorylation of ERK1/2 and JNK and expression of COX-2 increased in HBV WTtransfected/extract-treated cells, but not in HBV WTtransfected cells or in cells treated with extract alone (Fig 5d). These results suggest that IL-6 upregulation in HBV-transfected/extract-treated HepG2 cells is mediated by both increased COX-2 expression (via ERK1/2 and 


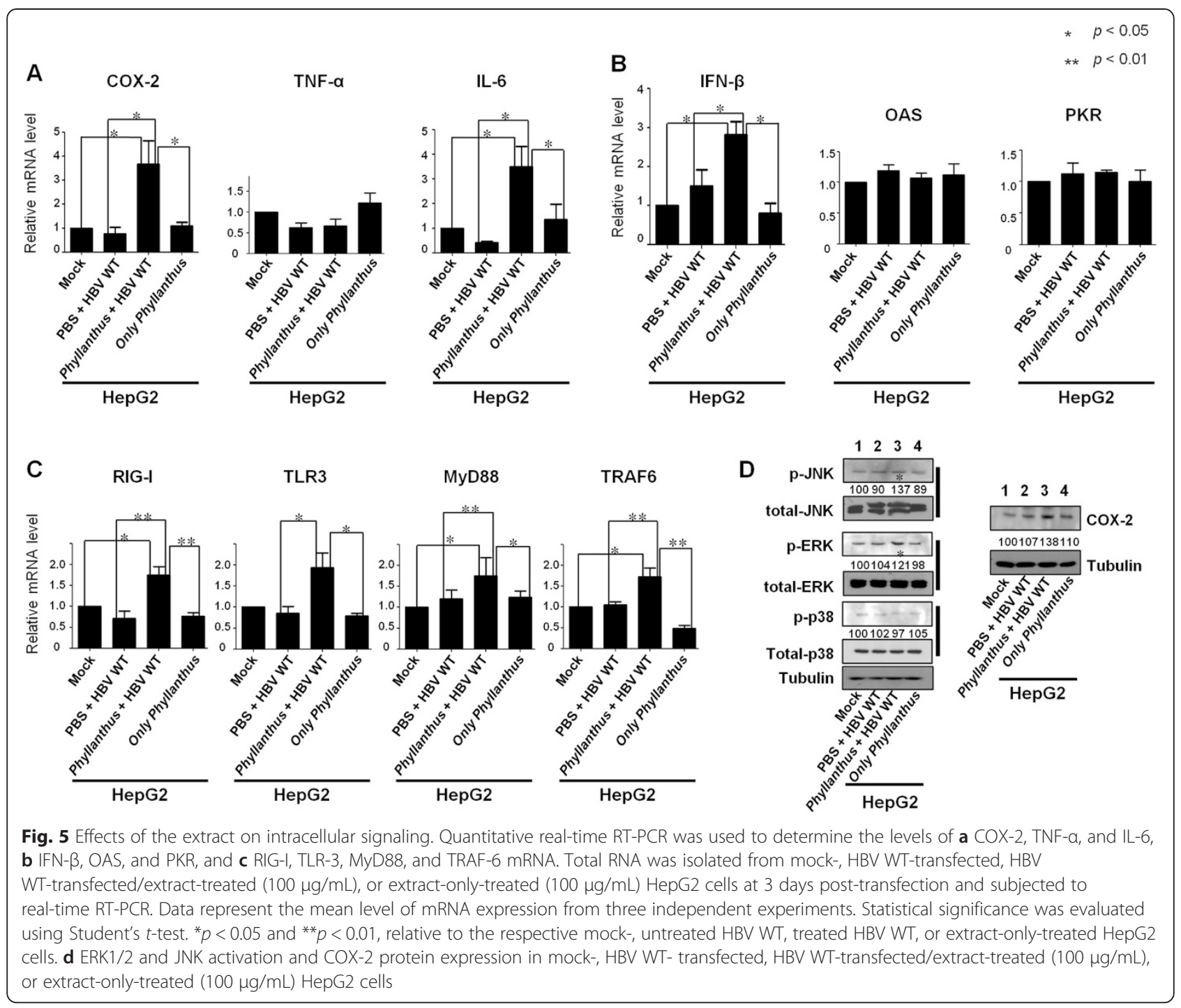

JNK activation) and increased RIG-I, TLR-3, MyD88, and TRAF-6 expression. Taken together, these data suggest that Phyllanthus extract inhibits HBV replication in HepG2 cells by activating the innate immune response by triggering intracellular signaling cascades (e.g., the ERK1/2 and JNK pathways), leading to the induction of COX-2 and IL-6.

\section{Discussion}

The Phyllanthus species has long been utilized as an herbal medicine, including as an anti-HBV agent. Here, we demonstrated that Phyllanthus extract has antiviral activity against LMV-resistant HBV mutants (Fig. 4 and Table 1). We also showed that the antiviral activity of Phyllanthus extract was not due to inhibition of intracellular HBV RNA and C protein expression, core particle formation, or pgRNA encapsidation (Fig. 2). Therefore, to examine the mechanism underlying Phyllanthus- mediated inhibition of HBV DNA replication (Figs. 2 and 4), we analyzed the expression of intracellular signaling molecules. We found increased expression of TLR-3, RIG-I, TRAF-6, and MyD88, COX-2, IL-6, and IFN- $\beta$ in HepG2 cells transfected with WT HBV and then exposed to Phyllanthus extract, but not in HBV WT-transfected HepG2 cells or in HepG2 cells exposed to extract alone (Fig. 5c). This suggests that the extract triggers the innate immune response and/or inflammatory responses, thereby inhibiting HBV replication.

Upregulated IFN- $\beta$ expression (Fig. $5 \mathrm{~b}$ ) suggests that Phyllanthus might induce IFN-mediated antiviral responses via IFN-inducible OAS and PKR genes. However, we did not observe OAS and PKR upregulation in HBV WT-transfected/extract-treated HepG2 cells (Fig. 5b). Since HepG2 cells harbor inherent defects in IFN-mediated antiviral responses [48], and IFN- $\alpha / \beta$ only modestly inhibits HBV replication in HepG2 cells [49], it 
appears that IFN-mediated responses may not be the major mechanism underlying the antiviral activity of the extract. However, we cannot exclude the possibility that other IFN-inducible cellular factors, such as apolipoprotein B mRNA-editing enzyme catalysis polypeptide 1like 3G (APOBEC3G) or human cytidine deaminase may be involved in limiting HBV replication without affecting pgRNA packaging [50]. IFN- $\alpha$-inducible expression of APOBEC3G has been reported in human hepatocytes, and IFN-responsive elements in the APOBEC3G promoter have been identified [50]. In addition, the DDX3 DEAD box (an RNA helicase) is involved in augmenting IFN-regulatory factor signaling by interacting with TANK-binding kinase $1 / \mathrm{I}$ KB kinase $\varepsilon$ [51]. Several studies demonstrate that cellular factors, such as APOBEC3G and DDX3, are incorporated into core particles and interact with HBV P protein, thereby inhibiting reverse transcription $[52,53]$.

The HBV X protein (HBx) and HIV gp120 stimulate COX-2 via the Ras-Raf-mitogen-activated protein kinase cascade, JNK, nuclear factor- $\mathrm{kB}$, and the Janus kinase/ signal transducers and activators of transcription signaling pathways [54-57]. Unlike $\mathrm{HBx}$ over-expressed cells [55], we found that COX-2 expression was not increased in HBV WT-transfected cells (Fig. 5a and d, lanes 2). Since upregulated expression of COX-2 mRNA and protein was observed only in HBV WT-transfected/extracttreated HepG2 cells (Fig. 5a and d, lanes 3), expression of COX-2 and IL- 6 may be triggered in HBV replicating cells in the presence of Phyllanthus extract. Upregulation of COX-2 expression via activation of the ERK1/2 and/or JNK pathways may play a role in the observed antiviral activity (Fig. 5d, lane 3). IL-6 regulates early HBV gene expression and inhibits HBV replication by activating the ERK $1 / 2$ and JNK pathways [58]. We speculate that increased IFN- $\beta$, IL- 6 , and COX-2 expression in HBV WT-transfected/Phyllanthus extract-treated HepG2 cells may induce the expression of IFN-inducible genes and/or different inflammatory mediators, which then inhibit HBV replication.

Taken together, the data presented herein suggest three possible mechanisms underlying the anti-HBV activity of Phyllanthus extract: (i) Phyllanthus extract directly inhibits hepadnaviral P protein [38]; (ii) because Phyllanthus extract alone did not induce a signaling cascade in HepG2 cells (Fig. 5), Phyllanthus extract works in conjunction with HBV replication and/or HBV protein and RNA expression to inhibit HBV replication by inducing IFN- $\beta$, COX-2, and IL-6 expression; (iii) since intracellular HBV RNAs, proteins, and core particles were unaffected by Phyllanthus extract (Fig. 2c-d), these molecules might stimulate the innate immune response to further inhibit HBV replication. These hypotheses are not mutually exclusive and they may work in concert with each other.

\section{Conclusion}

The results presented herein demonstrate that Phyllanthus extract effectively inhibits the replication of LMV-resistant HBV. Phyllanthus extract appears to inhibit HBV replication by inducing the expression of IFN- $\beta$, COX-2, and IL- 6 , which in turn activate the innate immune response. Thus, Phyllanthus extract may be a therapeutic agent useful for the management of LMV-resistant CHB patients; However, the detailed antiviral mechanisms and in vivo efficacy require further investigation.

\section{Additional files}

Additional file 1: Primers for realtime RT-PCR or PCR. (TIFF $1258 \mathrm{~kb}$ )

Additional file 2: MTT assay to measure the cytotoxicity of

Phyllanthus urinaria koreanis extract. HepG2 and Huh7 cells were exposed to varying concentrations of Phyllanthus extract (50-1200 $\mu \mathrm{g} /$ $\mathrm{mL}$ ) for $48 \mathrm{~h}$ and $\mathrm{CC}_{50}$ values determined in an MTT assay. The $\mathrm{CC}_{50}$ was defined as the concentration of extract that reduced cell viability to $50 \%$ of that of the control (cells untreated by extract). (TIFF $1052 \mathrm{~kb}$ )

\section{Abbreviations}

HBV: Hepatitis B virus; IFN- $\beta$ : Interferon-beta; COX-2: Cyclooxygenase-2; IL-6: Interleukin-6; LMV: Lamivudine; HBsAg: HBV surface antigen; HBcAg: HBV core antigen; pgRNA: Pregenomic RNA.

\section{Competing interests}

The authors have no competing interest to declare.

\section{Authors' contributions}

JJ carried out the experiments. KK and JJ analyzed the data. KK and JJ wrote the paper. All authors read and approved the final manuscript.

\section{Acknowledgments}

This work was supported by a National Research Foundation of Korea Grant funded from the Korean Government (NRF-2009-0089134). Jaesung Jung was supported by the BK21 program (Korean Ministry of Education).

\section{Author details}

${ }^{1}$ Department of Microbiology, Ajou University School of Medicine, Woncheon-dong 5, Suwon 443-721, Korea. ${ }^{2}$ Department of Biomedical Science, Graduate School of Ajou University, Woncheon-dong 5, Suwon, Korea. ${ }^{3}$ Institute for Clinical Research, CHA Bundang Medical Center, CHA University, Seongnam, Gyeonggi-do, Korea. ${ }^{4}$ Department of Internal Medicine, CHA Bundang Medical Center, CHA University, Seongnam, Gyeonggi-do, Korea.

Received: 23 April 2015 Accepted: 22 July 2015

Published online: 29 July 2015

\section{References}

1. Brechot C. Pathogenesis of hepatitis B virus-related hepatocellular carcinoma: old and new paradigms. Gastroenterology. 2004;127:S56-61.

2. Chisari FV, Isogawa M, Wieland SF. Pathogenesis of hepatitis B virus infection. Pathol Biol. 2010;58:258-66.

3. Guidotti LG, Chisari FV. Immunobiology and pathogenesis of viral hepatitis. Annu Rev Pathol. 2006;1:23-61.

4. Seeger C, Ganem D, Harold EV. Biochemical and genetic evidence for the hepatitis B virus replication strategy. Science. 1986;232:477-84.

5. Dienstag JL. Hepatitis B Virus Infection. N Engl J Med. 2008;359:1486-500.

6. Delaney WE, Yang H, Westland CE, Das K, Arnold E, Gibbs CS, et al. The hepatitis B virus polymerase mutation rtV173L is selected during lamivudine therapy and enhances viral replication in vitro. J Virol. 2003;77:11833-41.

7. Shaw T, Bartholomeusz A, Locarnini S. HBV drug resistance: mechanisms, detection and interpretation. J Hepatol. 2006;44:593-606. 
8. Zoulim F, Locarnini S. Hepatitis B Virus Resistance to Nucleos(t)ide Analogues. Gastroenterology. 2009;137:1593-608.

9. Ono-Nita SK, Kato N, Shiratori Y, Masaki T, Lan KH, Carrilho FJ, et al. YMDD Motif in Hepatitis B Virus DNA Polymerase Influences on Replication and Lamivudine Resistance: A Study by In Vitro Full-Length Viral DNA Transfection. Hepatology. 1999;29:939-45.

10. Niesters HG, De Man RA, Pas SD, Fries E, Osterhaus AD. Identification of a new variant in the YMDD motif of the hepatitis $B$ virus polymerase gene selected during lamivudine therapy. J Med Microbiol. 2002:51:695-9

11. Bozdayi AM, Uzunalimoglu O, Turkyılmaz AR, Aslan N, Aslan N, Sezgin O, et al. YSDD: a novel mutation in HBV DNA polymerase confers clinical resistance to lamivudine. J Viral Hepat. 2003;10:256-65.

12. Ogata N, Fujii K, Takigawa S, Nomoto M, Ichida T, Asakura H. Novel patterns of amino acid mutations in the hepatitis B virus polymerase in association with resistance to lamivudine therapy in japanese patients with chronic hepatitis B. J Med Virol. 1999;59:270-6.

13. Chong Y, Stuyver L, Otto MJ, Schinazi RF, Chu CK. Mechanism of antiviral activities of 3'-substituted L-nucleosides against 3TC resistant HBV polymerase: a molecular modelling approach. Antivir Chem Chemother. 2003;14:309-19.

14. Villeneuve J-P, Durantel D, Durantel S, Westland C, Xiong S, Brosgart CL, et al. Selection of a hepatitis B virus strain resistant to adefovir in a liver transplantation patient. J Hepatol. 2003;39:1085-9.

15. Lee YS, Chung YH, Kim JA, Kim SE, Shin JW, Kim KM, et al. Hepatitis B virus with rtL80V/I mutation associates with poor response to adefovir dipivoxil therapy. Liver Int. 2009;29:552-6.

16. Tenney DJ, Levine SM, Rose RE, Walsh AW, Weinheimer SP, Discotto L, et al. Clinical emergence of entecavir-resistant hepatitis $B$ virus requires additional substitutions in virus already resistant to Lamivudine. Antimicrob Agents Chemother. 2004;48:3498-507.

17. Yanni YN, Henry LY. A review of telbivudine for the management of chronic hepatitis B virus infection. Drug Eval. 2008;4:1351-61.

18. Yuen MF, Lai CL. Adefovir dipivoxil in chronic hepatitis B infection. Expert Opin Pharmacother. 2004;5:2361-7.

19. Van Bömmel F, Zöllner B, Sarrazin C, Spengler U, Hüppe D, Möller B, et al. Tenofovir for patients with lamivudine-resistant hepatitis $B$ virus (HBV) infection and high HBV DNA level during adefovir therapy. Hepatology. 2006:44:318-25.

20. Delmas J, Schorr O, Jamard C, Gibbs C, Trépo C, Hantz O, et al. Inhibitory effect of adefovir on viral DNA synthesis and covalently closed circular DNA formation in duck hepatitis B virus-infected hepatocytes in vivo and in vitro. Antimicrob Agents Chemother. 2002;46:425-33.

21. King RW, Ladner SK, Miller TJ, Zaifert K, Perni RB, Conway SC, et al. Inhibition of human hepatitis B virus replication by AT-61, a phenylpropenamide derivative, alone and in combination with (-)b-L- 2',3'-dideoxy-3'thiacytidine. Antimicrob Agents Chemother. 1998:42:3179-86.

22. Delaney WE, Edwards R, Colledge D, Shaw T, Furman P, Painter $G$, et al. Phenylpropenamide derivatives AT-61 and AT-130 inhibit replication of wild-type and lamivudine-resistant strains of hepatitis $B$ virus in vitro. Antimicrob Agents Chemother. 2002:46:3057-60.

23. Wang GF, Shi LP, Zuo JP. Anti-hepatitis B virus drugs in clinical and preclinical development. Virol Sin. 2008;2:137-45.

24. Weber $\mathrm{O}$, Schlemmer KH, Hartmann E, Hagelschuer I, Paessens A, Graef E, et al. Inhibition of human hepatitis B virus (HBV) by a novel non-nucleosidic compound in a transgenic mouse model. Antiviral Res. 2002;54:69-78.

25. Deres K, Schroder CH, Paessens A, Goldmann S, Hacker HJ, Weber O, et al. Inhibition of hepatitis B virus replication by drug-induced depletion of nucleocapsids. Science. 2003;299:893-6.

26. Weinberg MS, Arbuthnot P. Progress in the use of RNA interference as a therapy for chronic hepatitis B virus infection. Genome Med. 2010;2:28-34.

27. Ely A, Naidoo T, Mufamadi S, Crowther C, Arbuthnot P. Expressed anti-HBV primary microRNA shuttles inhibit viral replication efficiently in vitro and in vivo. Mol Ther. 2008;16:1105-12.

28. Iwamoto M, Watashi K, Tsukuda S, Aly HH, Fukasawa M, Fujimoto A, et al. Evaluation and identification of hepatitis $B$ virus entry inhibitors using HepG2 cells overexpressing a membrane transporter NTCP. Biochem Biophys Res Commun. 2014;17:808-13.

29. Wang GF, Shia LP, Ren YD, Liu QF, Liu HF, Zhang RJ, et al. Anti-hepatitis B virus activity of chlorogenic acid, quinic acid and caffeic acid in vivo and in vitro. Antiviral Res. 2009;83:186-90.
30. Kim HJ, Yoo HS, Kim JC, Park CS, Choi MS, Kim M, et al. Antiviral effect of Curcuma longa Linn extract against hepatitis B virus replication. J Ethnopharmacol. 2009;124:189-96.

31. Zhao G, Yin Z, Dong J. Antiviral efficacy against hepatitis B virus replication of oleuropein isolated from Jasminum officinale L. var. grandiflorum. J. J Ethnopharmacol. 2009;125:265-8.

32. Shuangsuo D, Zhengguo Z, Yunru C, Xin Z, Baofeng W, Lichao Y, et al. Inhibition of the replication of hepatitis B virus in vitro by emodin. Med Sci Monit. 2006;12:BR302-6.

33. Wu XN, Wang GJ. Experimental studies of oxymatrine and its mechanisms of action in hepatitis B and C viral infections. Chin J Dig Dis. 2004;5:12-6.

34. Guo Q, Zhao L, You Q, Yang Y, Gu H, Song G, et al. Anti-hepatitis B virus activity of wogonin in vitro and in vivo. Antiviral Res. 2007;74:16-24.

35. Penolazzi L, Lampronti I, Borgatti M, Khan MT, Zennaro M, Piva R, et al. Induction of apoptosis of human primary osteoclasts treated with extracts from the medicinal plant Emblica officinalis. BMC Complement Altern Med. 2008;30(8):59.

36. Kusirisin W, Srichairatanakool S, Lerttrakarnnon P. Antioxidative activity, polyphenolic content and anti-glycation effect of some Thai medicinal plants traditionally used in diabetic patients. Med Chem. 2009;5:139-47.

37. Ogata T, Higuchi H, Mochida S. HIV-1 reverse transcriptase inhibitor from Phyllanthus niruri. AIDS Res Hum Retroviruses. 1992;8:1937-44.

38. Venkateswaran PS, Millman I, Blumberg BS. Effect of extract from Phyllanthus niruri on hepatitis B and woodchuck hepatitis Viruses: In vitro and in vivo studies. Proc Natl Acad Sci U S A. 1987;84:274-8.

39. Ott M, Thyagarajan SP, Gupta S. Phyllanthus amarus suppresses hepatitis B virus by interrupting interactions between HBV enhancer I and cellular transcription factors. Eur J Clin Invest. 1997;27:908-15.

40. Lee CD, Ott M, Thyagarajan SP, Shafritz DA, Burk RD, Gupta S. Phyllanthus amarus down-regulates hepatitis B virus mRNA transcription and replication. Eur J Clin Invest. 1996;26:1069-76

41. Lam WY, Leung KT, Law PT, Lee SM, Chan HL, Fung KP, et al. Antiviral Effect of Phyllanthus nanus Ethanolic Extract Against Hepatitis B Virus (HBV) by Expression Microarray Analysis. J Cell Biochem. 2006;97:795-812

42. Shin MS, Kang EH, Lee YI. A flavonoid from medicinal plants blocks hepatitis $B$ virus-e antigen secretion in HBV-infected hepatocytes. Antiviral Res. 2005;67:163-8

43. Kim HY, Park GS, Kim EG, Kang SH, Shin HJ, Park S, et al. Oligomer synthesis by priming deficient polymerase in hepatitis B virus core particle. Virology. 2004;322:22-30.

44. Mahdi ES, Noor AM, Sakeena MH, Abdullah GZ, Abdulkarim M, Sattar MA. Identification of phenolic compounds and assessment of in vitro antioxidants activity of $30 \%$ ethanolic extracts derived from two Phyllanthus species indigenous to Malaysia. Afr J Pharm Pharmacol. 2011:5:1967-78.

45. Calixto JB, Santos AR, Cechinel Filho V, Yunes RA. A review of the plants of the genus Phyllanthus: their chemistry, pharmacology, and therapeutic potential. Med Res Rev. 1998;18:225-58.

46. Kim H-Y, Eo E-Y, Park HP, Kim YC, Park S, Shin HJ, et al. Medicinal herbal extracts of Sophorae radix, Acanthopanacis cortex, Sanguisorbae radix and Torilis fructus inhibit coronavirus replication in vitro. Antivir Ther 2010;15:697-709

47. Sharma M, Anderson SA, Schoop R, Hudson JB. Induction of multiple pro-inflammatory cytokines by respiratory viruses and reversal by standardized Echinacea, a potent antiviral herbal extract. Antiviral Res. 2009:83:165-70

48. Keskinen P, Nyqvist M, Sareneva T, Pirhonen J, Melean K, Julkunen I. Impaired Antiviral Response in Human Hepatoma Cells. Virology. 1999;263:364-75

49. Biermer M, Puro R, Schneider RJ. Tumor necrosis factor alpha inhibition of hepatitis B virus replication involves disruption of capsid Integrity through activation of NF-kappaB. J Virol. 2003;77:4033-42.

50. Tanaka Y, Marusawa H, Seno H, Matsumoto Y, Ueda Y, Kodama Y, et al. Anti-viral protein APOBEC3G is induced by interferon-alpha stimulation in human hepatocytes. Biochem Biophys Res Commun. 2006;341:314-9.

51. Soulat D, Burckstummer T, Westermayer S, Goncalves A, Bauch A, Stefanovic A, et al. The DEAD-box helicase DDX3X is a critical component of the TANK-binding kinase 1-dependent innate immune response. EMBO J. 2008;27:2135-46. 
52. Kock J, Blum HE. Hypermutation of hepatitis B virus genomes by APOBEC3G, APOBEC3C and APOBEC3H. J Gen Virol. 2008;89:1184-91.

53. Wang H, Kim SH, Ryu WS. DDX3 DEAD-Box RNA Helicase Inhibits Hepatitis B Virus Reverse Transcription by Incorporation into Nucleocapsids. J Virol. 2009;83:5815-24.

54. Lara-Pezzi E, Gomez-Gaviro MV, Galvez BG, Mira E, Iniguez MA, Fresnon M, et al. The hepatitis $B$ virus $X$ protein promoter tumor cell invasion by inducing membrane type matrix metalloproteinase- 1 and cyclooxygenase-2 expression. J Clin Invest. 2002;110:1831-8.

55. Cho HK, Cheong KJ, Kim HY, Cheong JH. Endoplasmic reticulum stress induced by hepatitis B virus X protein enhances cyclo-oxygenase 2 expression via activating transcription factor 4. Biochem J. 2011;435:431-9.

56. Corasaniti MT, Bellizzi C, Russo R, Colica C, Amantea D, Rezo GD. Caspase-1 inhibitors abolish deleterious enhancement of COX-2 expression induced by HIV-1 gp120 in human neuroblastoma cells. Toxicol Lett. 2003;139:213-9.

57. Hung J-H, Su I-J, Lei H-Y, Wang H-C, Lin W-C, Chang W-T, et al. Endoplasmic Reticulum Stress Stimulates the Expression of Cyclooxygenase-2 through Activation of NF-kB and pp 38 Mitogen-activated Protein Kinase. J Biol Chem. 2004;279:46384-92.

58. Hösel M, Quasdorff M, Wiegmann K, Webb D, Zedler U, Broxtermann M, et al. Not interferon, but interleukin-6 controls early gene expression in hepatitis B virus infection. Hepatology. 2009;50:1773-82

\section{Submit your next manuscript to BioMed Central and take full advantage of:}

- Convenient online submission

- Thorough peer review

- No space constraints or color figure charges

- Immediate publication on acceptance

- Inclusion in PubMed, CAS, Scopus and Google Scholar

- Research which is freely available for redistribution 